\title{
Gastric-and-Intestinal Mixed Intestinal Metaplasia Is Irreversible Point with Eradication of Helicobacter pylori
}

\author{
Yuka Kiriyama1, Tomomitsu Tahara ${ }^{2}$, Tomoyuki Shibata², Masaaki Okubo², \\ Mitsuru Nakagawa', Asako Okabe' ${ }^{1}$, Naoki Ohmiya ${ }^{2}$, Makoto Kuroda', Atsushi Sugioka³ \\ Masao Ichinose $^{4}$, Masae Tatematsu ${ }^{5}$, Tetsuya Tsukamoto ${ }^{*}$ \\ ${ }^{1}$ Department of Diagnostic Pathology, School of Medicine, Fujita Health University, Toyoake, Aichi, Japan \\ ${ }^{2}$ Department of Gastroenterology, School of Medicine, Fujita Health University, Toyoake, Aichi, Japan \\ ${ }^{3}$ Department of Hepatobiliary and Liver Transplant Surgery, School of Medicine, Fujita Health University, \\ Toyoake, Japan \\ ${ }^{4}$ Second Department of Internal Medicine, Wakayama Medical University, Wakayama, Japan \\ ${ }^{5}$ Japan Bioassay Research Center, Hadano, Japan \\ Email: *ttsukamt@fujita-hu.ac.jp
}

Received 9 March 2016; accepted 17 April 2016; published 20 April 2016

Copyright (C) 2016 by authors and Scientific Research Publishing Inc.

This work is licensed under the Creative Commons Attribution International License (CC BY).

http://creativecommons.org/licenses/by/4.0/

(c) (i) Open Access

\section{Abstract}

Helicobacter pylori (H. pylori) represents an important factor in the development of atrophic gastritis, intestinal metaplasia (IM), and gastric cancer. Eradication of $H$. pylori has been reported to prevent gastric cancer only in cases without atrophy or IM. However, histological changes with eradication have yet to be fully clarified. We evaluated $38 \mathrm{H}$. pylori-positive cases before and after eradication at the gland level; pyloric glands were classified as showing gastric proper (G) and IM gland types, with the latter including gastric-and-intestinal mixed IM (GI-IM) and solely intestinal IM (I-IM), depending on the remaining gastric phenotypes. On eradication, acute and chronic inflammation attenuated rapidly and gradually, respectively, whereas levels of MUC5AC and MUC6 expression were not markedly altered. Gland width, size of nuclei and cytoplasm and their ratio in surface foveolar epithelium, the number of Ki-67-positive cells and the length of the proliferating zone in each gland were significantly decreased in G glands after eradication compared with those in GI-IM and I-IM. The number of mitotic phase cells, positive for phosphorylated histone $\mathrm{H} 3$ at serine 28, was increased in both types of IM compared to that in G glands in the $H$. pylori-infected state, but unexpectedly remained unchanged with eradication. These results suggest that GI-IM, as the beginning of IM, could represent a histological irreversible point with eradication and be considered as a "histological point of no return".

${ }^{*}$ Corresponding author.

How to cite this paper: Kiriyama, Y., et al. (2016) Gastric-and-Intestinal Mixed Intestinal Metaplasia Is Irreversible Point with Eradication of Helicobacter pylori. Open Journal of Pathology, 6, 93-104.

http://dx.doi.org/10.4236/ojpathology.2016.62012 


\section{Keywords}

\section{Helicobacter pylori, Chronic Atrophic Gastritis, Intestinal Metaplasia, Eradication, Stomach}

\section{Introduction}

Gastric cancer remains the most common type of cancer and the second leading cause of cancer-related deaths in Japan, despite recent decreasing trends. Worldwide, this malignancy remains the fourth most frequent cause of morbidity and the second-most widespread cause of cancer death especially in East Asian countries, $41 \%$ from China and 11\% from Japan in 2002 [1]-[3]. Helicobacter pylori (H. pylori) was discovered by Warren and Marshall in 1983 and suggested as a causative factor for gastric disorders [4]. H. pylori infection has been illustrated to be a consequential risk factor for the development of chronic atrophic gastritis and intestinal metaplasia (IM) [5]. In humans, IM has been extensively analyzed and attracted attention of pathologists as a precancerous lesion. We have proposed a novel classification depending on emerging intestinal properties together with remaining gastric phenotypes. With this classification, IM could be divided into two main types, gastric-and-intestinal mixed IM (GI-IM) and solely intestinal IM (I-IM); the former still possess gastric components including MUC5AC-positive foveolar epithelium and/or MUC6-positive atrophied pyloric gland cells and the latter consists only of intestinal epithelium characterized by MUC2 possessing goblet cells or CD10-positive absorptive cell with nuclear CDX2 expression with or without Paneth cells [6] [7]. The Mongolian gerbil (Meriones unguiculatus) model was established to show successful $H$. pylori infection and subsequent chronic active gastritis and emergence of IM [8]. Regenerative glands often developed and proliferated beyond the muscularis mucosae to form cystic dilated glands in the submucosa, designated as heterotopic proliferative glands (HPGs). HPGs initially consisted of only gastric epithelial cells but gradually possessed intestinal epithelial cells 25 weeks after infection to form GI-IM, and then finally containing Paneth cells to compose I-IM. These results explain $H$. pylori infection as initially causing chronic gastritis, then induce GI-IM, and finally progress to I-IM dependent on the duration of $H$. pylori-induced inflammation [9]. Taking into account both human and animal data, IM was considered to represent a serial and simultaneous progression of atrophy and intestinalization via GI-IM toward finally I-IM with $H$. pylori infection.

Several case-control studies have revealed a positive correlation between $H$. pylori infection and gastric carcinogenesis [10]-[13]. Based on these epidemiological findings, the World Health Organization (WHO)/International Agency for Research on Cancer (IARC) defined H. pylori as a "definite carcinogen" in 1994 [14]. In Mongolian gerbil models, $H$. pylori infection strongly promoted chemical carcinogen-induced gastric carcinogenesis [15] [16]. In turn, eradication of the bacteria proved effective in preventing carcinogenesis in $H$. pylori-infected carcinogen-treated gerbils; the earlier, the more effectively [17] [18]. In human trials, Fukase et al. [19] reported that eradication of $H$. pylori was effective for preventing metachronous gastric carcinoma. However, Wong et al. [20] and Yanaoka et al. [21] indicated that eradication was not practically effective in preventing gastric carcinogenesis for subjects who had already passed the irreversible point and suffered from severe atrophic and metaplastic gastritis. In this regard, the pathological findings that really represent risk factors and the point beyond which recovery cannot be achieved with eradication of $H$. pylori remain unclear.

In this study, we classified pyloric glands as gastric proper (G), GI-IM, and I-IM, then analyzed the reversibility of each gland type after eradicating $H$. pylori in an attempt to identify histological points of irreversibility.

\section{Materials and Methods}

\subsection{Study Subjects}

The subjects had been analyzed for $H$. pylori infection using the ${ }^{13} \mathrm{C}$-urea breath test (using UBIT tablets, Otsuka Pharmaceutical Co., Ltd., Tokyo, Japan). Briefly, the patients were judged " $H$. pylori infected" if ${ }^{13} \mathrm{C}$-carbon dioxide was detected in their exhaled breath when ${ }^{13} \mathrm{C}$-urea was taken, which should be decomposed into ${ }^{13} \mathrm{C}$-carbon dioxide $\left(\mathrm{CO}_{2}\right)$ and ammonia with $\mathrm{H}$. pylori-derived urease in the stomach. The patients underwent eradication of the bacteria with $30 \mathrm{mg}$ of lansoprazole b.d. (bis die, twice a day), $200 \mathrm{mg}$ of clarithromycin b.d, and $750 \mathrm{mg}$ of amoxicillin b.d. for 1 week as described [22] in the Endoscopy Center at Fujita Health University Hospital between 2003 and 2013. This study using human tissue was conducted with approval from the Institu- 
tional Review Board of Fujita Health University. Thirty-eight patients, who have undergone gastric biopsies before and after eradication, were selected, from whom informed consents had already been obtained. Biopsy specimens were classified into $\mathrm{H}$. pylori-positive $[\mathrm{Hp}(+)]$ and successfully eradicated $[\mathrm{Hp}(-)]$ groups. Thirty-one patients underwent stomach biopsies both before and after eradication once each. Seven cases were biopsied at least twice after eradication. Five cases were failed for eradication of the bacteria and were included in an $\mathrm{Hp}\left(^{+}\right)$ group. Total of $43 \mathrm{Hp}(+)$ and $45 \mathrm{Hp}(-)$ samples were analyzed. Mean age was $59.2 \pm 14.5$ years (median, 63.5 years). Male/female ratio was 28/10. In the $\mathrm{Hp}(-)$ group, biopsies were sampled after $14.7 \pm 17.1$ months (median, 4 months). Among these, 24 biopsies were taken between 2 and 6 months after eradication $[\mathrm{Hp}(-)<6 \mathrm{M}]$, and 21 were between 7 and 69 months $[\mathrm{Hp}(-)>7 \mathrm{M}]$.

\subsection{Inflammatory Score}

Degree of inflammation was scored according to the updated Sydney system [23] including H. pylori, neutrophils, mononuclear cells, atrophy of antrum and corpus region, and IM into scores of: 0 , normal; 1 , mild; 2, moderate; and 3, marked. If immunohistochemical analysis could not detect $H$. pylori, final judgment of the infection was determined according to the ${ }^{13} \mathrm{C}$-urea breath test and was scored as 1 in case of the infection-positive.

\subsection{Immunohistochemistry and Classification of Each Gland with Gastric and Intestinal Phenotypes}

Tissue samples embedded in paraffin blocks were utilized for hematoxylin (Merck KGaA, Darmstadt, Germany) and eosin (Muto Pure Chemicals, Co., Ltd., Tokyo, Japan) (HE) staining and immunohistochemical analyses. For the immunohistochemical detection of gastrointestinal phenotypic markers, antibodies against MUC5AC (clone CLH2; Novocastra, Newcastle-upon-Tyne, UK), MUC6 (clone CLH5; Novocastra), and CDX2 (CDX288; BioGenex, San Ramon, CA) were applied. Ki-67 antibody (clone MIB-1; DAKO Japan, Tokyo, Japan) was used to detect proliferative cells and anti-phosphorylated histone H3 at serine 28 (H3S28ph, clone HTA28; generously providedby Dr. Masaaki Inagaki, Aichi Cancer Center Research Institute, Nagoya, Japan) was utilized for visualization of mitotic phase nuclei [24]. H. pyloriwas immunohistochemically detected using a polyclonal antibody (DAKO). All immunohistochemical procedures were performed using iView DAB universal kits with Ventana Benchmark Ultra apparatus according to the instructions from the manufacturer (Roche Diagnostics, Tokyo, Japan). Briefly, sections were deparaffinized, treated with CC1 antigen retrieval buffer (5 mM ethylenediaminetetraacetic acid, $\mathrm{pH}$ 8.0), and incubated with the primary antibodies described above. Then, the sections were treated with the universal secondary antibody (mixture of anti-mouse and anti-rabbit antibodies), visualized with 3, 3'-diaminobenzidine, and counter-stained with hematoxylin. Glands were classified into G and IMglands, with the latter including GI-IM and I-IM according to the morphology and immunoexpression of gastric and intestinal markers, as previously described [7].

\subsection{Mucin Core Protein Expression}

Expression of MUC5AC was analyzed in the whole area of mucosa, whereas MUC6 was judged in the antrum and corpus separately. Evaluations were made semiquantitatively according to the staining intensity into scores of: 0 , none; 1 , weak; 2 , moderate; and 3 , strong.

\subsection{Histological Analyses}

Antral region was chosen to evaluate progression of IM, since corpus region rarely possessed GI-IM. Diameter of the glands at the widest part was measured in the shallow region of the foveolar epithelium in G, GI-IM, and I-IM glands to monitor hyperplastic or hypertrophic responses to $H$. pylori infection. Height of the cytoplasm $(\mathrm{C})$, nucleus $(\mathrm{N})$, and nucleus-to-cytoplasm (N/C) ratio were also measured at the same points to assess relative nuclear enlargement and disturbance of polarity at the cellular level. In the relatively deeper zone, length of the Ki-67-positive proliferative region was measured in each gland. Numbers of Ki-67- and H3S28ph-positive cells per gland were also counted.

\subsection{Statistical Analysis}

Quantitative values are expressed as means \pm standard deviation (SD) and medians, and differences between 
means were statistically analyzed using the Kruskal-Wallis test followed by Dunn's multiple comparisons using Prism 6 software (GraphPad Software, La Jolla, CA). Values of $P<0.05$ were considered statistically significant.

\section{Results}

\subsection{Gastritis, Atrophy, and Intestinal Metaplasia}

The amount of $H$. pylori, degree of inflammatory cell infiltrates, atrophy of mucosa, and IM are described in Table 1 for $\mathrm{Hp}(+)$ and $\mathrm{Hp}(-)$ groups. H. pylori disappeared in the $\mathrm{Hp}(-)$ group. Neutrophils were drastically decreased after successful eradication. Mononuclear cells gradually showed a relative decrease after eradication. In contrast, atrophy in both the antrum and corpus and IM were not significantly altered.

\subsection{Mucin Expression}

Expression of MUC5AC in the surface foveolar epithelium and those of MUC6 in the antrum (pyloric mucosa) and corpus (fundic mucosa) were evaluated, but no significant alteration was found (Table 1).

\subsection{Analysis of Surface Foveolar Epithelium}

In the $H$. pylori-infected condition $[\mathrm{Hp}(+)]$, gastric-type foveolar glands show hyperplastic and hypertrophic proliferation, resulting in enlargement of the diameter of the glands, lengthening of the foveolar cytoplasm, increasing size of nuclei, and increased N/C ratio (Figure 1).

Diameters of foveolar glands were $125.0 \pm 43.9 \mu \mathrm{m}, 108.6 \pm 22.1 \mu \mathrm{m}$, and $116.7 \pm 27.8 \mu \mathrm{m}$ in G, GI-IM, and I-IM glands in the $\mathrm{Hp}(+)$ group, compared to $74.8 \pm 22.6 \mu \mathrm{m}, 100.8 \pm 21.2 \mu \mathrm{m}$, and $102.6 \pm 27.8 \mu \mathrm{m}$ in the $\mathrm{Hp}(-)$ group, respectively. The numbers of the glands analyzed are 26, 14, and 19 in G, GI, and I in the Hp(+) groups, and 22, 10, and 18 in the $\mathrm{Hp}(-)$ group, respectively. Diameter of $\mathrm{G}$ glands was significantly narrowed after eradication of $H$. pylori $[\mathrm{Hp}(-) / G]$ compared to $\mathrm{Hp}(+) / G$, and also became significantly slimmer than the $\mathrm{Hp}(-)$ /I group (Figure 2(a)).

Heights of foveolar cell (C) were $31.3 \pm 12.4 \mu \mathrm{m}, 34.5 \pm 10.5 \mu \mathrm{m}, 36.4 \pm 10.4 \mu \mathrm{m}, 25.2 \pm 6.5 \mu \mathrm{m}, 35.2 \pm 9.9$ $\mu \mathrm{m}$, and $34.1 \pm 11.7 \mu \mathrm{m}$ in $\mathrm{Hp}(+) / G, H p(+) / G I, H p(+) / I, H p(-) / G, H p(-) / G I$, and $\mathrm{Hp}(-) / I$ groups, respectively. The numbers of the glands analyzed are $45,28,39,44,19$, and 36, respectively. A decrease was seen in $\mathrm{Hp}(-) / \mathrm{G}$ compared with $\mathrm{Hp}(+) / G$, indicating significant alleviation with eradication. However, height of the IM epithelium, including both GI-IM and I-IM, was not altered by eradication of the bacteria (Figure 2(b)).

Heights of $\mathrm{N}$ from the basal layer were $16.6 \pm 7.7 \mu \mathrm{m}, 16.9 \pm 5.8 \mu \mathrm{m}, 13.3 \pm 4.7 \mu \mathrm{m}, 8.5 \pm 3.0 \mu \mathrm{m}, 15.2 \pm 4.3$ $\mu \mathrm{m}$, and $15.0 \pm 6.6 \mu \mathrm{m}$ in $\mathrm{Hp}(+) / G, H p(+) / G I, H p(+) / I, H p(-) / G, H p(-) / G I$, and $\mathrm{Hp}(-) / I$ groups, respectively. The analyzed numbers are $44,28,39,44,19$, and 36 , respectively. $\mathrm{N}$ moved to the luminal side from the surrounding basal region in the $H$. pylori-infected state, but lay above the basal layer after eradication of the bacteria in gastric foveolar epithelium $[\mathrm{Hp}(+) / \mathrm{G}$ vs. $\mathrm{Hp}(-) / G]$. In contrast, $\mathrm{N}$ localization was not significantly changed between $\mathrm{Hp}(+)$ and $\mathrm{Hp}(-)$ conditions in IM (Figure 2(c)).

$\mathrm{N} / \mathrm{C}$ ratio was further evaluated to assess the effect of eradication, and was $51.9 \% \pm 11.3 \%, 49.5 \% \pm 12.4 \%$, $37.2 \% \pm 8.7 \%, 33.9 \% \pm 8.0 \%, 45.6 \% \pm 14.1 \%$, and $44.7 \% \pm 13.4 \%$, in the $\mathrm{Hp}(+) / G, \mathrm{Hp}(+) / G I, H p(+) / I$, $\mathrm{Hp}(-) / \mathrm{G}, \mathrm{Hp}(-) / \mathrm{GI}$, and $\mathrm{Hp}(-) / \mathrm{I}$ groups, respectively. The analyzed numbers are 44, 28, 39, 44, 19, and 36, respectively. In the $H$. pylori-positive condition, N/C ratio was highest in G glands. With eradication, the ratio in

Table 1. Summary of updated Sydney system and mucin core protein expression.

\begin{tabular}{|c|c|c|c|c|c|c|c|c|c|c|}
\hline & $\begin{array}{c}\text { No. of } \\
\text { biopsies }\end{array}$ & H. pylori & Neutrophils & $\begin{array}{c}\text { Mononuclear } \\
\text { cells }\end{array}$ & $\begin{array}{l}\text { Atrophy } \\
\text { (antrum) }\end{array}$ & $\begin{array}{l}\text { Atrophy } \\
\text { (corpus) }\end{array}$ & $\begin{array}{c}\text { Intestinal } \\
\text { metaplasia }\end{array}$ & MUC5AC & $\begin{array}{c}\text { MUC6 } \\
\text { (antrum) }\end{array}$ & $\begin{array}{l}\text { MUC6 } \\
\text { (corpus) }\end{array}$ \\
\hline $\mathrm{Hp}(+)$ & 43 & $1.09 \pm 0.29$ & $1.79 \pm 1.01$ & $2.00 \pm 0.65$ & $1.61 \pm 0.93$ & $1.33 \pm 0.87$ & $0.81 \pm 1.16$ & $2.51 \pm 0.77$ & $2.24 \pm 0.71$ & $1.82 \pm 0.98$ \\
\hline $\begin{array}{c}\mathrm{Hp}(-) \\
<6 \mathrm{M}\end{array}$ & 24 & $\begin{array}{c}0.00 \pm \\
0.00^{* * * *}\end{array}$ & $\begin{array}{c}0.29 \pm \\
0.62^{* * * *}\end{array}$ & $1.54 \pm 0.51^{*}$ & $1.62 \pm 0.80$ & $1.00 \pm 1.41$ & $0.67 \pm 1.09$ & $2.54 \pm 0.59$ & $2.25 \pm 0.72$ & $2.00 \pm 0.82$ \\
\hline $\begin{array}{c}\mathrm{Hp}(-) \\
>7 \mathrm{M}\end{array}$ & 21 & $\begin{array}{c}0.00 \pm \\
0.00^{* * * * *}\end{array}$ & $\begin{array}{c}0.38 \pm \\
0.50^{* * * *}\end{array}$ & $1.48 \pm 0.51^{* *}$ & $2.15 \pm 0.55$ & $0.75 \pm 1.04$ & $1.43 \pm 1.25$ & $2.52 \pm 0.68$ & $2.54 \pm 0.90$ & $2.00 \pm 1.07$ \\
\hline
\end{tabular}

${ }^{*} \mathrm{P}<0.05,{ }^{* *} \mathrm{P}<0.01,{ }^{* * * *} \mathrm{P}<0.0001$ compared with $\mathrm{Hp}(+)$ groups. 
G
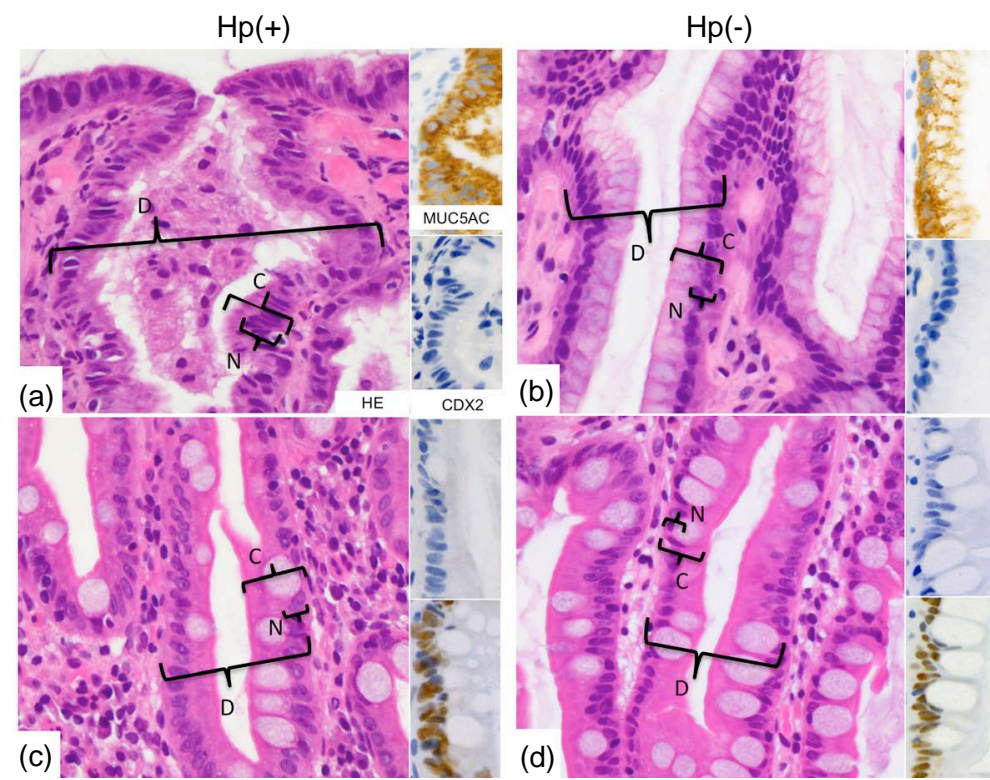

Figure 1. Histological change of foveolar epithelium with or without intestinal metaplasia with eradication. (a) and (b) $\mathrm{G}$ type glands with $H$. pylori infection $[\mathrm{Hp}(+)]$ and after eradication $[\mathrm{Hp}(-)]$ with expression of gastric marker, MUC5AC. (c) and (d) $\mathrm{Hp}(+)$ and $\mathrm{Hp}(-) \mathrm{I}$ type glands with nuclear CDX2 staining as an intestinal marker. D, diameter of foveolar glands; $\mathrm{C}$, height of the foveolar cells; $\mathrm{N}$, size of the nuclei. HE staining, Inset, top and bottom each, MUC5AC and CDX2 immunostaining. Original magnification, $400 \times$.
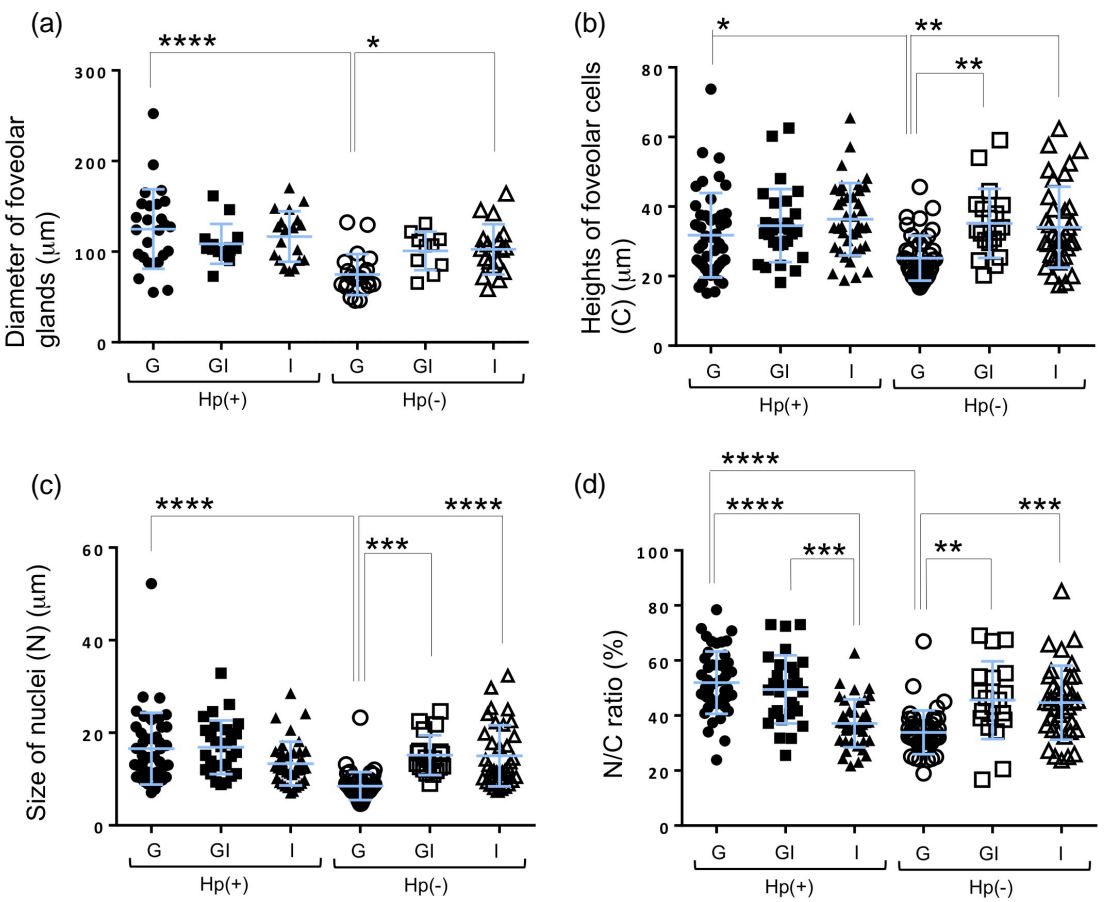

Figure 2. Analysis of surface foveolar epithelium in G, GI-IM, and I-IM glands between $\mathrm{Hp}(+)$ and $\mathrm{Hp}(-)$ groups. (a) Diameter of foveolar glands; (b) height of cytoplasm of foveolar cells; (c) size of nuclei. (d) N/C ratio of foveolar cells. In all of four factors, significant decrease was observed in $\mathrm{Hp}(-) / \mathrm{G}$ glands after eradication compared with those in $\mathrm{Hp}(+) / G$. Since IM glands were not recovered, $\mathrm{Hp}(-) / \mathrm{G}$ shows significant lower values after eradication. ${ }^{*} P<0.05,{ }^{* *} P<0.01,{ }^{* * *} P<0.001,{ }^{* * * *} P<0.0001$. 
G gland $[\mathrm{Hp}(-) / G]$ decreased dramatically and was the lowest compared with $\mathrm{Hp}(-) / \mathrm{GI}$ and $\mathrm{Hp}(-)$ /I (Figure 2(d)).

\subsection{Analysis of Proliferative Zone}

The proliferative zone was localized at the bottom of foveolar epithelium above pyloric glands in G and GI-IM. In I-IM, however, the proliferative zone was localized at the bottom of the gland, since pyloric glands showed almost complete atrophic change. Gastric glands showed regenerative proliferation with $H$. pylori infection, and this proliferation was drastically reduced with eradication, whereas IM glands (both GI-IM and I-IM) did not show alleviation in terms of Ki-67-positive cells. Surprisingly, the number of H3S28ph-positive mitotic cells was unchanged with eradication in G glands, and was much higher in IM glands irrespective of $H$. pylori infection (Figure 3).

Lengths of the proliferative zone were determined as the region of Ki-67-positive cells in each gland and were $276.2 \pm 98.8 \mu \mathrm{m}, 356.5 \pm 111.3 \mu \mathrm{m}, 297.7 \pm 77.0 \mu \mathrm{m}, 169.8 \pm 43.3 \mu \mathrm{m}, 370.6 \pm 98.4 \mu \mathrm{m}$, and $358.5 \pm 81.5 \mu \mathrm{m}$, respectively, in the $\mathrm{Hp}(+) / \mathrm{G}, \mathrm{Hp}(+) / \mathrm{GI}, \mathrm{Hp}(+) / \mathrm{I}, \mathrm{Hp}(-) / \mathrm{G}, \mathrm{Hp}(-) / \mathrm{GI}$, and $\mathrm{Hp}(-) / \mathrm{I}$ groups. The numbers of glands analyzed are $25,14,18,17,14$, and 10 , respectively. The proliferative zone became smaller only in G-type glands after eradication of $H$. pylori in contrast to IM glands (including GI-IM and I-IM). After eradication, the proliferative zone was significantly shorter in G glands compared with GI-IM and I-IM (Figure 4(a)).

Numbers of Ki-67-positive cells per gland were $92.4 \pm$ 40.1, $132.4 \pm$ 55.5, $101.6 \pm 44.6,30.6 \pm 17.9,150.2 \pm$ 51.9 , and $141.6 \pm 39.5$, respectively. The analyzed numbers are $25,14,18,17,14$, and 10 , respectively. The number in $\mathrm{Hp}(-) / G$ was significantly reduced after eradication, whereas those in $\mathrm{Hp}(-) / \mathrm{GI}$ and $\mathrm{Hp}(-) / \mathrm{I}$ were not (Figure 4(b)).

Mean numbers of H3S28ph-positive mitotic cells per gland were $1.04 \pm 0.87,1.70 \pm 0.97,2.42 \pm 1.32,0.70 \pm$ 0.76, $2.36 \pm 1.52$, and $2.34 \pm 2.41$, respectively in $\mathrm{Hp}(+) / G, H p(+) / G I, H p(+) / I, ~ H p(-) / G, H p(-) / G I$, and $\mathrm{Hp}(-) / I$ groups. The numbers analyzed are 36, 29, 21, 26, 28, and 8, respectively. The number of H3S28ph-positive cells

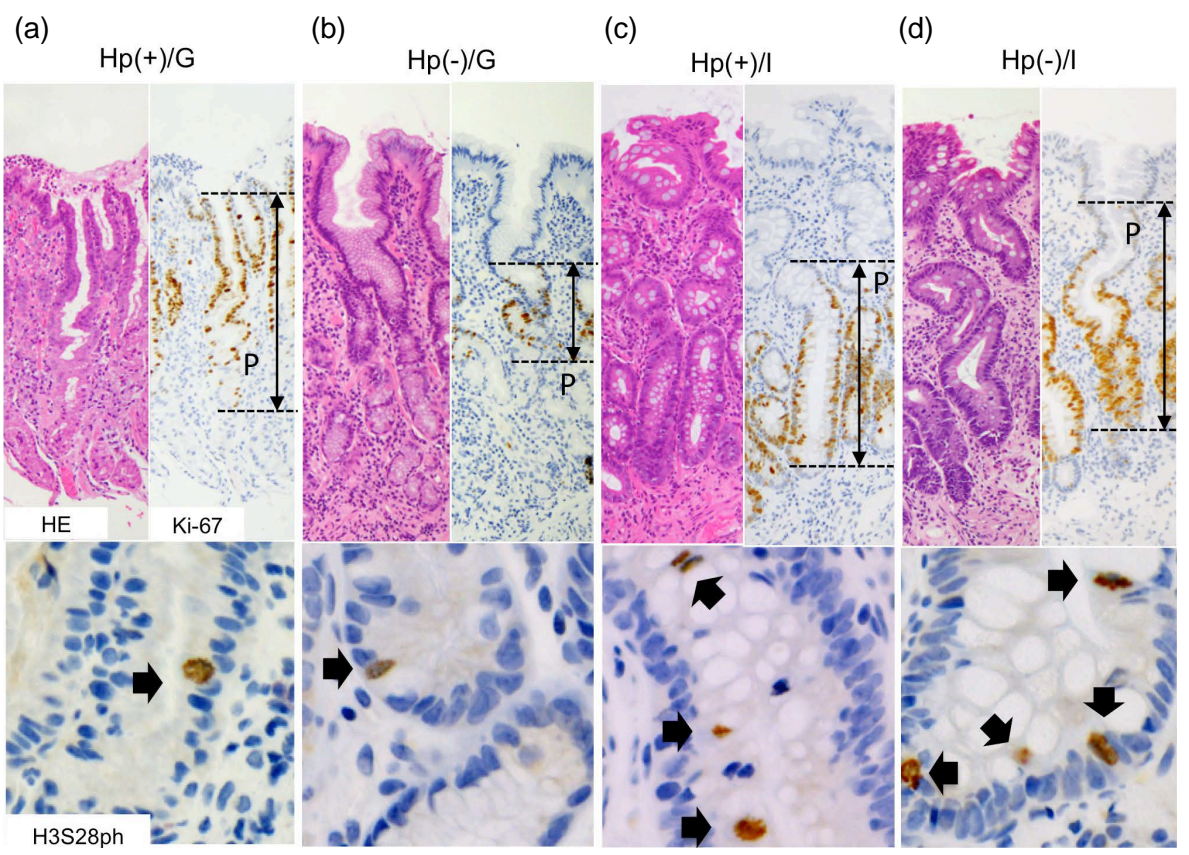

Figure 3. Histological change of proliferative zones with or without IM before and after successful eradication. (a) and (b) $\mathrm{G}$ type glands with $H$. pylori infection $[\mathrm{Hp}(+)]$ and after eradication $[\mathrm{Hp}(-)]$. Proliferative zone localizes in the lower part of foveolar epithelium above partially atrophied pyloric glands. (c) and (d) $\mathrm{Hp}\left(^{+}\right)$and $\mathrm{Hp}(-)$ I type glands. Proliferative zone stays at the bottom of the gland, since pyloric gland has been already completely atrophied. P, length of the proliferative zones. Arrow, H3S-28ph positive mitotic cells. Top left, HE staining, top right, Ki-67 immunostaining, Original magnification, 100×. Bottom, H3S28ph immunostaining. Original magnification, 400×. 

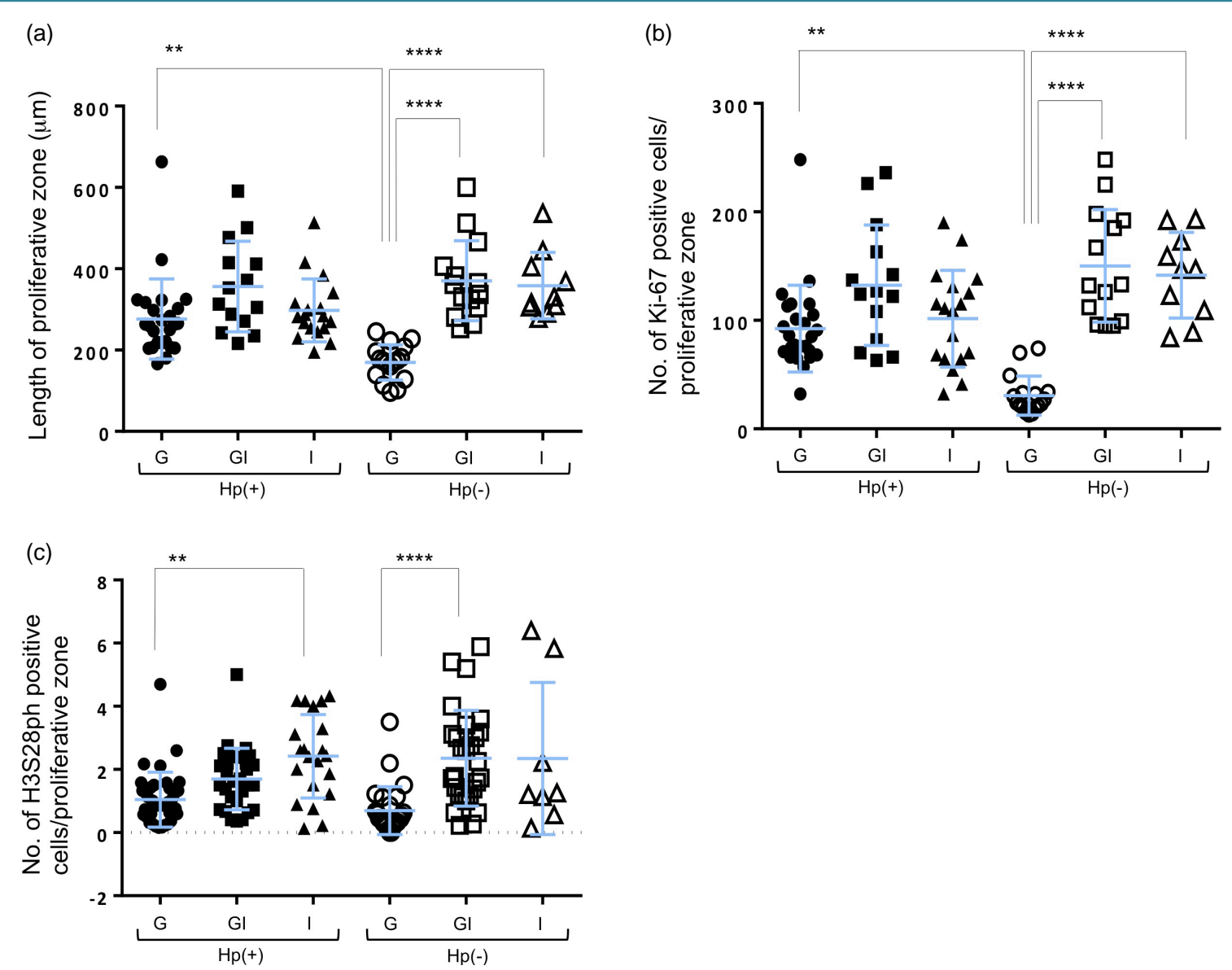

Figure 4. Analysis of proliferative zone in G, GI-IM, and I-IM glands between $\mathrm{Hp}(+)$ and $\mathrm{Hp}(-)$ groups. (a) Length of the proliferative zone; (b) the number of Ki-67 positive cells/proliferative zone. In (a) and (b), significant decrease was observed in $\mathrm{Hp}(-) / \mathrm{G}$ glands after eradication compared with those in $\mathrm{Hp}(+) / \mathrm{G}$. IM glands were not recovered upon eradication. $\mathrm{Hp}(-) / \mathrm{G}$ shows significant lower values compared with $\mathrm{Hp}(-) / \mathrm{GI}$ and $\mathrm{Hp}(-) / \mathrm{I}$ after eradication; (c) the number of H3S29ph positive cells/proliferative zone. Significant lower values in $\mathrm{Hp}(+) / \mathrm{G}$ and $\mathrm{Hp}(-) / \mathrm{G}$ compared with IM counterparts, not being affected with eradication. ${ }^{* *} P<0.01,{ }^{* * * *} P<0.0001$.

in $\mathrm{Hp}(+) / I$ glands was increased significantly compared to that in $\mathrm{Hp}(+) / \mathrm{G}$ glands. After eradication, numbers of mitotic phase cells in each gland were not significantly changed, with the number in $\mathrm{Hp}(-) / \mathrm{G}$ glands still significantly lower than that in $\mathrm{Hp}(-)$ /GI glands (Figure 4(c)).

\section{Discussion}

Since the discovery of $\mathrm{H}$. pylori, this organism has been clarified to play a major role in the induction of chronic atrophic gastritis and development of IM [25] [26]. In the current analysis, we analyzed whether and how far this serial process of atrophy and intestinalization could be recovered to normal gastric mucosa with eradication of $H$. pylori.

In previous trials, several reports did not always show the improvement of gastric atrophy and IM with eradication of H. pylori [27]-[29] as in our analysis. In contrast, other publications have shown the effectiveness of eradication for improving gastric lesions in the antrum or corpus, at least in part [30]-[33]. Although recent findings tend to show recovery of atrophy and controversial results for IM, it is difficult to precisely compare the degree of factors for the updated Sydney System in small biopsy samples. Exacerbation of atrophic gastritis is often coupled with development and progression of IM. However, since the schematic view of the updated Sydney System [23] describes atrophy and IM separately, only mild atrophy without IM might be acknowledged as "atrophy". Since the observation period after eradication in our analysis was relatively short, for $14.7 \pm 17.1$ months (median, 4 months), finding of histological changes might have been hindered. 
We have analyzed the expression of mucin core protein before and after $H$. pylori eradication. However, no significant changes in expression of mucin core protein were seen in our scoring system, despite alleviation of foveolar epithelium in G glands in this analysis. A large discrepancy was found in the expression of mucin core proteins among our and previous reports. Matsuzwa et al. [34] reported that MUC6 in pyloric gland cells were increased in $H$. pylori-associated gastritis and decreased to almost normal levels after eradication. In contrast, Fichman and Niv [35] and Kang et al. [36] analyzed histological changes to reveal up-regulation of MUC6 mucin core protein with eradication of $H$. pylori. These two reports, however, showed controversial results for MUC5AC. This might have been caused by sampling deviation of biopsy specimens and evaluation methods.

Eradication of $H$. pylori alleviated hyperplastic and hypertrophic enlargement of foveolar epithelium only in G-type, but not in GI-IM and I-IM. Consistent with our results, endoscopic observation showed that enlarged and elongated gastric pits improved to small oval or round pits, whereas no such change was observed in subjects with severe atrophy and IM [22].

In the antrum, the proliferative zone is localized between the surface foveolar epithelium and pyloric glands, and is characterized by Ki-67 immunopositivity. Our results showed that proliferative zones widened and numbers of Ki-67-positive cells per gland were increased in all G, GI-IM, and I-IM glands in H. pylori-positive cases. Nonetheless, upon eradication of $\mathrm{H}$. pylori, the proliferative region and Ki-67-positive cells were significantly decreased only in G-type glands. Murakami et al. [37] observed mucosal cell proliferation in H. pylori-associated gastritis and showed that eradication of the bacteria markedly reduced proliferation in both the antrum and corpus. In contrast, El-Zimaity et al. [38] documented that antral mucosal proliferation was sustained despite successful eradication of $H$. pylori. However, the presence of IM was not clearly described in their reports. Erkan et al. [39] compared Ki-67-positive proliferative index in IM and chronic gastritis and showed a significantly higher index in IM.

Histone H3 is phosphorylated at serine 28 during the $\mathrm{M}$ phase in the cell cycle, being detected with HTA28 antibody [24]. In G-type glands harboring no IM, H3S28ph-positive cells were not increased with H. pylori infection, which was unexpectedly not altered by eradication in contrast to the proliferative zone characterized as the Ki-67-positive region. On the other hand, in IM glands including both GI-IM and I-IM, the number of M-phase cells increased in the $H$. pylori-infected state and did not recover with eradication. In contrast to our results, Hibi et al. [40] reported that mitotic index was elevated in the non-eradicated group, but was significantly decreased in the eradicated group. Since this report does not precisely identify what types of gland we reevaluated, mixtures of G, GI-IM, and I-IM glands could have been used for evaluation. Taking into account all the data, the beginning of IM could represent a point of irreversible change, despite eradication of $H$. pylori (Figure 5).

To prevent gastric lesions, eradication of $H$. pylori has been approved not only for gastric cancer or peptic ulcer patients but also for cases of $H$. pylori-induced chronic gastritis. Several reports suggested that successful eradication might reduce the occurrence of metachronous gastric cancer after endoscopic resection of early gastric cancer in prospective studies up to 3-year follow up [19] [41] or in a retrospective study [42]. Contrasting with the above favorable analyses, other reports have not always shown welcome consequences with the eradication of $H$. pylori. Wong et al. [20] conducted a 7.5-year randomized controlled trial in China and revealed that eradication of $H$. pylori was clarified to significantly decrease the subsequent development of gastric cancer only in the subgroup without gastric atrophy, IM, or dysplasia but the overall incidence of gastric cancer did not differ significantly between participants receiving $H$. pylori eradication and those receiving placebo. Yanaoka et al. [21] performed a prospective study to clarify the risk of gastric carcinogenesis with simultaneously monitoring degree of chronic gastritis using serum pepsinogen level and pepsinogen I/II ratio and observed significant reduction in cancer incidence in pepsinogen test-negative subjects with mild gastritis after $H$. pylori eradication over a mean period of $9.3 \pm 0.7$ years. Maehata et al. [43] performed a retrospective multicenter study including $268 \mathrm{H}$. pylori-positive patients who had undergone endoscopic resection of gastric cancer and revealed severe mucosal atrophy as an independent risk factor for the development of metachronous cancers despite unimproved overall risk. Another meta-analysis [44] supports the idea that eradication of $H$. pylori is effective only in the subgroup without IM or dysplasia. Animal models support the idea that $H$. pylori eradication was useful to prevent gastric carcinogenesis especially when performed in an earlier period [15]-[18] [25] [26].

\section{Conclusion}

In conclusion, as mentioned above, mucosal damage with IM may not recover to gastric-type mucosa, so the 


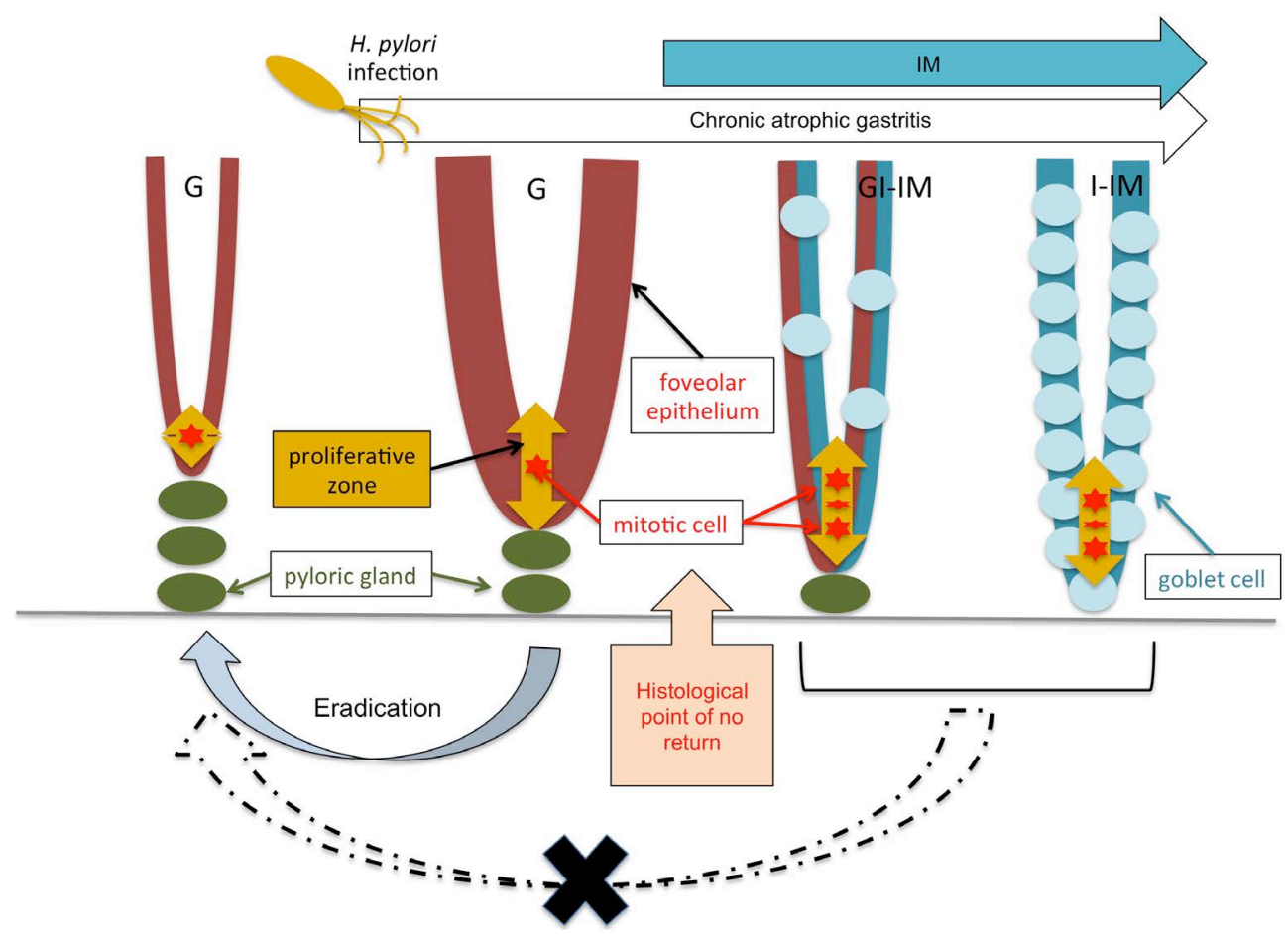

Figure 5. Progression of chronic atrophic gastritis and IM and reversibility of histological change with eradication of $\mathrm{H}$. pylori. Chronic atrophic gastritis progress with process of IM. "Histological point of no return” indicates irreversible point. G, gastric-type gland; GI-IM, gastric-and-intestinal mixed intestinal metaplasia; I-IM, solely intestinal-intestinal metaplasia.

shift from G to GI-IM would represent a candidate for a "histological point of no return" with eradication of $H$. pylori. As a result, it is advised that $H$. pylori would better be eradicated at a younger age before the development of IM, to most effectively prevent gastric carcinogenesis.

\section{Acknowledgements}

This study was supported, in part, by a Health Labour Sciences Research Grant from the Ministry of Health, Labour and Welfare, Japan and by Grants-in-Aid from the Ministry of Education, Science, Sports and Culture of Japan. We wish to thank Mr. Yutaka Hirasawa, Ms. Satomi Ito, and Ms. Maki Fujiwara for their expert technical assistance. HTA28 antibody was a generous gift from Drs. Hidemasa Goto and Masaki Inagaki, Division of Biochemistry, Aichi Cancer Center Research Institute, Nagoya, Japan.

\section{Conflict of Interests}

The authors have no conflict of interests to disclose.

\section{References}

[1] Inoue, M. and Tsugane, S. (2005) Epidemiology of Gastric Cancer in Japan. Postgraduate Medical Journal, 81, 419424. http://dx.doi.org/10.1136/pgmj.2004.029330

[2] Shen, L., Shan, Y.S., Hu, H.M., Price, T.J., Sirohi, B., Yeh, K.H., Yang, Y.H., Sano, T., Yang, H.K., Zhang, X., Park, S.R., Fujii, M., Kang, Y.K. and Chen, L.T. (2013) Management of Gastric Cancer in Asia: Resource-Stratified Guidelines. The Lancet Oncology, 14, e535-e547. http://dx.doi.org/10.1016/S1470-2045(13)70436-4

[3] Parkin, D.M., Bray, F., Ferlay, J. and Pisani, P. (2005) Global Cancer Statistics, 2002. CA: A Cancer Journal for Clinicians, 55, 74-108. http://dx.doi.org/10.3322/canjclin.55.2.74

[4] Warren, J.R. and Marshall, B. (1983) Unidentified Curved Bacilli on Gastric Epithelium in Active Chronic Gastritis. Lancet, 1, 1273-1275. 
[5] Kuipers, E.J., Uyterlinde, A.M., Pena, A.S., Roosendaal, R., Pals, G., Nelis, G.F., Festen, H.P. and Meuwissen, S.G. (1995) Long-Term Sequelae of Helicobacter Pylori Gastritis. Lancet, 345, 1525-1528. http://dx.doi.org/10.1016/S0140-6736(95)91084-0

[6] Inada, K., Nakanishi, H., Fujimitsu, Y., Shimizu, N., Ichinose, M., Miki, K., Nakamura, S. and Tatematsu, M. (1997) Gastric and Intestinal Mixed and Solely Intestinal Types of Intestinal Metaplasia in the Human Stomach. Pathology International, 47, 831-841. http://dx.doi.org/10.1111/j.1440-1827.1997.tb03714.x

[7] Tsukamoto, T., Mizoshita, T. and Tatematsu, M. (2006) Gastric-and-Intestinal Mixed-Type Intestinal Metaplasia: Aberrant Expression of Transcription Factors and Stem Cell Intestinalization. Gastric Cancer, 9, 156-166. http://dx.doi.org/10.1007/s10120-006-0375-6

[8] Hirayama, F., Takagi, S., Yokoyama, Y., Iwao, E. and Ikeda, Y. (1996) Establishment of Gastric Helicobacter Pylori Infection in Mongolian Gerbils. Journal of Gastroenterology, 31, 24-28. http://dx.doi.org/10.1007/BF02347631

[9] Nozaki, K., Shimizu, N., Tsukamoto, T., Inada, K., Cao, X., Ikehara, Y., Kaminishi, M., Sugiyama, A. and Tatematsu, M. (2002) Reversibility of Heterotopic Proliferative Glands in Glandular Stomach of Helicobacter Pylori-Infected Mongolian Gerbils on Eradication. Japanese Journal of Cancer Research, 93, 374-381. http://dx.doi.org/10.1111/j.1349-7006.2002.tb01267.x

[10] Forman, D., Newell, D.G., Fullerton, F., Yarnell, J.W., Stacey, A.R., Wald, N. and Sitas, F. (1991) Association between Infection with Helicobacter Pylori and Risk of Gastric Cancer: Evidence from a Prospective Investigation. BMJ, 302, 1302-1305. http://dx.doi.org/10.1136/bmj.302.6788.1302

[11] Nomura, A., Stemmermann, G.N., Chyou, P.H., Kato, I., Perez-Perez, G.I. and Blaser, M.J. (1991) Helicobacter pylori Infection and Gastric Carcinoma among Japanese Americans in Hawaii. The New England Journal of Medicine, 325, 1132-1136. http://dx.doi.org/10.1056/NEJM199110173251604

[12] Parsonnet, J., Friedman, G.D., Vandersteen, D.P., Chang, Y., Vogelman, J.H., Orentreich, N. and Sibley, R.K. (1991) Helicobacter pylori Infection and the Risk of Gastric Carcinoma. The New England Journal of Medicine, 325, 1127-1131. http://dx.doi.org/10.1056/NEJM199110173251603

[13] Uemura, N., Okamoto, S., Yamamoto, S., Matsumura, N., Yamaguchi, S., Yamakido, M., Taniyama, K., Sasaki, N. and Schlemper, R.J. (2001) Helicobacter pylori Infection and the Development of Gastric Cancer. The New England Journal of Medicine, 345, 784-789. http://dx.doi.org/10.1056/NEJMoa001999

[14] IARC Working Group on the Evaluation of Carcinogenic Risks to Humans (1994) Infection with Helicobacter pylori. In: Schistosomes, Liver Flukes and Helicobacter pylori, World Health Organization/International Agency for Research on Cancer, Lyon, 177-241.

[15] Sugiyama, A., Maruta, F., Ikeno, T., Ishida, K., Kawasaki, S., Katsuyama, T., Shimizu, N. and Tatematsu, M. (1998) Helicobacter pylori Infection Enhances N-Methyl-N-Nitrosourea-Induced Stomach Carcinogenesis in the Mongolian Gerbil. Cancer Research, 58, 2067-2069.

[16] Shimizu, N., Inada, K., Nakanishi, H., Tsukamoto, T., Ikehara, Y., Kaminishi, M., Kuramoto, S., Sugiyama, A., Katsuyama, T. and Tatematsu, M. (1999) Helicobacter pylori Infection Enhances Glandular Stomach Carcinogenesis in Mongolian Gerbils Treated with Chemical Carcinogens. Carcinogenesis, 20, 669-676. http://dx.doi.org/10.1093/carcin/20.4.669

[17] Shimizu, N., Ikehara, Y., Inada, K., Nakanishi, H., Tsukamoto, T., Nozaki, K., Kaminishi, M., Kuramoto, S., Sugiyama, A., Katsuyama, T. and Tatematsu, M. (2000) Eradication Diminishes Enhancing Effects of Helicobacter pylori Infection on Glandular Stomach Carcinogenesis in Mongolian Gerbils. Cancer Research, 60, 1512-1514.

[18] Nozaki, K., Shimizu, N., Ikehara, Y., Inoue, M., Tsukamoto, T., Inada, K., Tanaka, H., Kumagai, T., Kaminishi, M. and Tatematsu, M. (2003) Effect of Early Eradication on Helicobacter pylori-Related Gastric Carcinogenesis in Mongolian Gerbils. Cancer Science, 94, 235-239. http://dx.doi.org/10.1111/j.1349-7006.2003.tb01426.x

[19] Fukase, K., Kato, M., Kikuchi, S., Inoue, K., Uemura, N., Okamoto, S., Terao, S., Amagai, K., Hayashi, S. and Asaka, M. (2008) Effect of Eradication of Helicobacter pylori on Incidence of Metachronous Gastric Carcinoma after Endoscopic Resection of Early Gastric Cancer: An Open-Label, Randomised Controlled Trial. Lancet, 372, 392-397. http://dx.doi.org/10.1016/S0140-6736(08)61159-9

[20] Wong, B.C., Lam, S.K., Wong, W.M., Chen, J.S., Zheng, T.T., Feng, R.E., Lai, K.C., Hu, W.H., Yuen, S.T., Leung, S.Y., Fong, D.Y., Ho, J. and Ching, C.K. (2004) Helicobacter pylori Eradication to Prevent Gastric Cancer in a High-Risk Region of China: A Randomized Controlled Trial. JAMA, 291, 187-194. http://dx.doi.org/10.1001/jama.291.2.187

[21] Yanaoka, K., Oka, M., Ohata, H., Yoshimura, N., Deguchi, H., Mukoubayashi, C., Enomoto, S., Inoue, I., Iguchi, M., Maekita, T., Ueda, K., Utsunomiya, H., Tamai, H., Fujishiro, M., Iwane, M., Takeshita, T., Mohara, O. and Ichinose, M. (2009) Eradication of Helicobacter pylori Prevents Cancer Development in Subjects with Mild Gastric Atrophy Identified by Serum Pepsinogen Levels. International Journal of Cancer, 125, 2697-2703.

http://dx.doi.org/10.1002/ijc.24591 
[22] Okubo, M., Tahara, T., Shibata, T., Nakamura, M., Yoshioka, D., Maeda, Y., Yonemura, J., Ishizuka, T., Arisawa, T. and Hirata, I. (2011) Changes in Gastric Mucosal Patterns Seen by Magnifying Nbi during H. Pylori Eradication. Journal of Gastroenterology, 46, 175-182. http://dx.doi.org/10.1007/s00535-010-0335-0

[23] Dixon, M.F., Genta, R.M., Yardley, J.H. and Correa, P. (1996) Classification and Grading of Gastritis. The Updated Sydney System. International Workshop on the Histopathology of Gastritis, Houston 1994. The American Journal of Surgical Pathology, 20, 1161-1181. http://dx.doi.org/10.1097/00000478-199610000-00001

[24] Hirata, A., Inada, K., Tsukamoto, T., Sakai, H., Mizoshita, T., Yanai, T., Masegi, T., Goto, H., Inagaki, M. and Tatematsu, M. (2004) Characterization of a Monoclonal Antibody, Hta28, Recognizing a Histone H3 Phosphorylation Site as a Useful Marker of M-Phase Cells. Journal of Histochemistry \& Cytochemistry, 52, 1503-1509. http://dx.doi.org/10.1369/jhc.4A6285.2004

[25] Tsukamoto, T. and Tatematsu, M. (2014) Role of Helicobacter pylori in Gastric Neoplasia. Current Infectious Disease Reports, 16, 402. http://dx.doi.org/10.1007/s11908-014-0402-4

[26] Tsukamoto, T., Toyoda, T., Mizoshita, T. and Tatematsu, M. (2013) Helicobacter pylori Infection and Gastric Carcinogenesis in Rodent Models. Seminars in Immunopathology, 35, 177-190. http://dx.doi.org/10.1007/s00281-012-0357-1

[27] Forbes, G.M., Warren, J.R., Glaser, M.E., Cullen, D.J., Marshall, B.J. and Collins, B.J. (1996) Long-Term Follow-Up of Gastric Histology after Helicobacter pylori Eradication. Journal of Gastroenterology and Hepatology, 11, 670-673. http://dx.doi.org/10.1111/j.1440-1746.1996.tb00312.x

[28] Satoh, K., Kimura, K., Takimoto, T. and Kihira, K. (1998) A Follow-Up Study of Atrophic Gastritis and Intestinal Metaplasia after Eradication of Helicobacter pylori. Helicobacter, 3, 236-240.

[29] Annibale, B., Aprile, M.R., D'Ambra, G., Caruana, P., Bordi, C. and Delle Fave, G. (2000) Cure of Helicobacter pylori Infection in Atrophic Body Gastritis Patients Does Not Improve Mucosal Atrophy but Reduces Hypergastrinemia and Its Related Effects on Body Ecl-Cell Hyperplasia. Alimentary Pharmacology \& Therapeutics, 14, 625-634. http://dx.doi.org/10.1046/j.1365-2036.2000.00752.x

[30] Ito, M., Haruma, K., Kamada, T., Mihara, M., Kim, S., Kitadai, Y., Sumii, M., Tanaka, S., Yoshihara, M. and Chayama, K. (2002) Helicobacter pylori Eradication Therapy Improves Atrophic Gastritis and Intestinal Metaplasia: A 5-Year Prospective Study of Patients with Atrophic Gastritis. Alimentary Pharmacology \& Therapeutics, 16, 14491456. http://dx.doi.org/10.1046/j.1365-2036.2002.01311.x

[31] Toyokawa, T., Suwaki, K., Miyake, Y., Nakatsu, M. and Ando, M. (2010) Eradication of Helicobacter pylori Infection Improved Gastric Mucosal Atrophy and Prevented Progression of Intestinal Metaplasia, Especially in the Elderly Population: A Long-Term Prospective Cohort Study. Journal of Gastroenterology and Hepatology, 25, 544-547. http://dx.doi.org/10.1111/j.1440-1746.2009.05995.x

[32] Kodama, M., Murakami, K., Okimoto, T., Sato, R., Uchida, M., Abe, T., Shiota, S., Nakagawa, Y., Mizukami, K. and Fujioka, T. (2012) Ten-Year Prospective Follow-Up of Histological Changes at Five Points on the Gastric Mucosa as Recommended by the Updated Sydney System after Helicobacter pylori Eradication. Journal of Gastroenterology, 47, 394-403. http://dx.doi.org/10.1007/s00535-011-0504-9

[33] Lee, Y.C., Chen, T.H., Chiu, H.M., Shun, C.T., Chiang, H., Liu, T.Y., Wu, M.S. and Lin, J.T. (2013) The Benefit of Mass Eradication of Helicobacter pylori Infection: A Community-Based Study of Gastric Cancer Prevention. Gut, 62, 676-682. http://dx.doi.org/10.1136/gutjnl-2012-302240

[34] Matsuzwa, M., Ota, H., Hayama, M., Zhang, M.X., Sano, K., Honda, T., Ueno, I., Akamatsu, T. and Nakayama, J. (2003) Helicobacter pylori Infection Up-Regulates Gland Mucous Cell-Type Mucins in Gastric Pyloric Mucosa. Helicobacter, 8, 594-600. http://dx.doi.org/10.1111/j.1523-5378.2003.00185.x

[35] Fichman, S. and Niv, Y. (2004) Histological Changes in the Gastric Mucosa after Helicobacter pylori Eradication. European Journal of Gastroenterology \& Hepatology, 16, 1183-1188.

http://dx.doi.org/10.1097/00042737-200411000-00017

[36] Kang, H.M., Kim, N., Park, Y.S., Hwang, J.H., Kim, J.W., Jeong, S.H., Lee, D.H., Lee, H.S., Jung, H.C. and Song, I.S. (2008) Effects of Helicobacter pylori Infection on Gastric Mucin Expression. Journal of Clinical Gastroenterology, 42 , 29-35. http://dx.doi.org/10.1097/MCG.0b013e3180653cb7

[37] Murakami, K., Fujioka, T., Kodama, R., Kubota, T., Tokieda, M. and Nasu, M. (1997) Helicobacter pylori Infection Accelerates Human Gastric Mucosal Cell Proliferation. Journal of Gastroenterology, 32, 184-188. http://dx.doi.org/10.1007/BF02936365

[38] El-Zimaity, H.M., Graham, D.Y., Genta, R.M. and Lechago, J. (2000) Sustained Increase in Gastric Antral Epithelial Cell Proliferation Despite Cure of Helicobacter pylori Infection. The American Journal of Gastroenterology, 95, 930-935. http://dx.doi.org/10.1111/j.1572-0241.2000.01932.x

[39] Erkan, G., Gonul, I.I., Kandilci, U. and Dursun, A. (2012) Evaluation of Apoptosis along with Bcl-2 and Ki-67 Ex- 
pression in Patients with Intestinal Metaplasia. Pathology, Research and Practice, 208, 89-93. http://dx.doi.org/10.1016/j.prp.2011.12.002

[40] Hibi, K., Mitomi, H., Koizumi, W., Tanabe, S., Saigenji, K. and Okayasu, I. (1997) Enhanced Cellular Proliferation and P53 Accumulation in Gastric Mucosa Chronically Infected with Helicobacter pylori. American Journal of Clinical Pathology, 108, 26-34.

[41] Uemura, N., Mukai, T., Okamoto, S., Yamaguchi, S., Mashiba, H., Taniyama, K., Sasaki, N., Haruma, K., Sumii, K. and Kajiyama, G. (1997) Effect of Helicobacter pylori Eradication on Subsequent Development of Cancer after Endoscopic Resection of Early Gastric Cancer. Cancer Epidemiology, Biomarkers \& Prevention, 6, 639-642.

[42] Bae, S.E., Jung, H.Y., Kang, J., Park, Y.S., Baek, S., Jung, J.H., Choi, J.Y., Kim, M.Y., Ahn, J.Y., Choi, K.S., Kim do, H., Lee, J.H., Choi, K.D., Song, H.J., Lee, G.H. and Kim, J.H. (2014) Effect of Helicobacter pylori Eradication on Metachronous Recurrence after Endoscopic Resection of Gastric Neoplasm. The American Journal of Gastroenterology, 109, 60-67. http://dx.doi.org/10.1038/ajg.2013.404

[43] Maehata, Y., Nakamura, S., Fujisawa, K., Esaki, M., Moriyama, T., Asano, K., Fuyuno, Y., Yamaguchi, K., Egashira, I., Kim, H., Kanda, M., Hirahashi, M. and Matsumoto, T. (2012) Long-Term Effect of Helicobacter pylori Eradication on the Development of Metachronous Gastric Cancer after Endoscopic Resection of Early Gastric Cancer. Gastrointestinal Endoscopy, 75, 39-46. http://dx.doi.org/10.1016/j.gie.2011.08.030

[44] Chen, H.N., Wang, Z., Li, X. and Zhou, Z.G. (2016) Helicobacter pylori Eradication Cannot Reduce the Risk of Gastric Cancer in Patients with Intestinal Metaplasia and Dysplasia: Evidence from a Meta-Analysis. Gastric Cancer, 19, 166-175. 